\title{
A comparative study of efficacy and safety of intramuscular carboprost and intravaginal misoprostol for cervical priming prior to first trimester surgical abortion
}

\author{
Gayatri Mathuriya*, Neha Verma, Shivangi Pandey
}

Department of Obstetrics and Gynecology, M. G. M. Medical College and M. Y. Hospital, Indore, Madhya Pradesh, India

Received: 05 May 2019

Revised: 01 October 2019

Accepted: 05 October 2019

\section{*Correspondence:}

Dr. Gayatri Mathuriya,

E-mail: drgayatrimathuriya@gmail.com

Copyright: () the author(s), publisher and licensee Medip Academy. This is an open-access article distributed under the terms of the Creative Commons Attribution Non-Commercial License, which permits unrestricted non-commercial use, distribution, and reproduction in any medium, provided the original work is properly cited.

\section{ABSTRACT}

Background: MTP Act no 34 of 1971 has been defined as Legal termination of pregnancy before the age of viability of fetus that is 20 weeks of gestation. There is a need to find a medical agent which can help in the process of abortion by speeding it up, with minimal side effects. The objective of this study was to compare the efficacy of I.M carboprost and intravaginal Misoprostol and to evaluate the safety profile of I.M carboprost and Intravaginal Misoprostol. To compare the cervical dilatation caused by I.M carboprost and intravaginal Misoprostol and to compare the blood loss and adverse effects of I.M carboprost and Intravaginal Misoprostol.

Methods: Prospective randomized experimental study including pregnant women up to 12 weeks of gestation opting for M.T.P. Study conducted on 200 patients selected from patients admitted in MGM Medical College and M.Y. Hospital, Indore and Kalyanmal Hospital, Indore during the period July 2014 to March 2015. They were randomly divided into 2 groups. Group A who received intramuscular injection of $250 \mathrm{mcg}$ of caboprost or Group B,which received $400 \mathrm{mcg}$ of vaginal Misoprostol 4 hours prior to suction evacuation.

Results: Intravaginal misoprostol achieves better cervical dilatation compared I.M carboprost which is statistically significant. Misoprostol is associated with higher blood loss as compared to I.M carboprost which is associated with nausea/vomiting \& more likelihood of loose stools and abdominal cramps which is proved statistically.

Conclusions: Intravaginal misoprostol is associated with higher blood loss as compared to I.M carboprost which is significant but intravaginal misoprostol achieves more cervical dilatation and causes less adverse events than I.M carboprost which is statistically more significant and therefore intravaginal misoprostol is the drug of choice for cervical priming prior to surgical abortion in terms of both efficacy and safety.

Keywords: Carboprost, Intravaginal, Misoprostol, Multigravida, Prostaglandin, Primigravida

\section{INTRODUCTION}

The Legal definition for abortion is the interruption of pregnancy before viability. Worldwide, around 28 per 1000 women opt for elective abortions annually. $49 \%$ of these abortions are unsafe. ${ }^{1}$ Cervical dilatation before suction evacuation is probably the most critical step of the procedure. ${ }^{2}$ Mechanical cervical dilatation in the first trimester has been associated with some risk of cervical injury and incompetence of the cervix resulting in premature labor and spontaneous abortion. Several chemical agents have been used in trying to prevent this mishap in the last few years. Prostaglandins have revolutionized the treatment of abortions. ${ }^{3}$ Although 
misoprostol (PGE1) was first introduced as a gastric ulcer protective agent, it became popular for its effect on cervical ripening and other advantages like less cervical injuries, minimal intraoperative blood loss, reduced requirement of general anesthetics, and availability in different dosage forms. ${ }^{3}$ Misoprostol can be administered orally, vaginally, sublingually, buccally or rectally. Pharmacokinetics studies comparing oral and vaginal administration have shown that vaginal misoprostol is associated with slower absorption, lower peak plasma levels and slower clearance, similar to an oral extended release preparation. ${ }^{4-6}$ Vaginal misoprostol is also associated with a greater overall exposure to the drug, area under the curve (AUC) and greater effects on the cervix and uterus. ${ }^{5}$ Carboprost is a synthetic analogue of PGF2alfa. It acts directly on the myometrium. This agent stimulates the gravid uterus, contractions are usually sufficient to induce abortion. ${ }^{7}$ This drug when given intramuscularly for cervical priming, though effective, is associated with too many side effects. ${ }^{8}$

Because in the today's era our main aim is that the patient get maximum satisfaction with least adverse effects with minimal hospital stay, it is in this view that we decided to find out that whether I.M carboprost or intravaginal misoprostol is more effective for cervical priming prior to first trimester MTP or missed abortion and which one of these is associated with less adverse effects and less blood loss.

\section{Aims and objectives}

- To compare the efficacy of I.M carboprost and Intravaginal Misoprostol and to evaluate the safety profile of I.M carboprost and intravaginal Misoprostol.

- To compare the cervical dilatation caused by I.M carboprost and Intravaginal Misoprostol and to compare the blood loss and adverse effects of I.M carboprost and intravaginal Misoprostol.

\section{METHODS}

The present study was a prospective randomized experimental study including pregnant women up to 12 weeks of gestation opting for medical termination of pregnancy conducted on 200 patients selected from patients registered in OPD and admitted in Department of Obstetrics and Gynecology in MGM Medical College and M.Y. Hospital, Indore and Kalyanmal Hospital, Indore during the period July 2014 to March 2015.

\section{Inclusion criteria}

- Primigravida/ multigravida with pregnancy of 12 weeks or below opting for MTP

- Primigravida/ multigravida with Missed abortion or abnormal fetus up to 12 weeks gestation.

\section{Exclusion criteria}

- Women with gestation $>12$ weeks

- Hypersensitivity to prostaglandins

- chronic disorder i.e. Asthma, cardio-vascular diseases, hepatic diseases, renal disorders

- $\quad$ Ectopic pregnancy

- Severe anemia

An informed consent was obtained following initial screening for inclusion. The study participation was voluntary.

\section{Patient variable and data collection}

- A detailed medical history and examination along with USG examination

- Initial pelvic examination to note the findings about the state of cervix, uterus and adnexa

- Admission at least 12 hours prior to procedure

- Required investigations esp. Rh typing. All Rhnegative patients received AntiD 300IU I.M

- Written informed consent

- Random allotment to group A or B, receiving 250 micrograms of Carboprost I.M 45 minutes prior or 400 micrograms of misoprostol intravaginally in the posterior fornix 4 hours prior to procedure respectively

- Procedure of MVA was done under I.V administration of atropine sulfate and $30 \mathrm{mg}$ pentazocine

- A pelvic examination at the start of procedure to note

a) Cervical status

b) Weather os closed or open

c) Whether dilatation has occurred, if so, to how many Hegars (mm).

- $\quad$ Procedure by suction evacuation using MVA

- At the end of procedure blood loss was assessed by pouring the collected material of MVA syringe into a graduated jar of $60 \mathrm{ml}$ after passing through a filter. The unfiltered material was then re-evaluated to separate the products of conception from the blood clots. Mass of the blood clots was also included in estimating the total blood loss

- Antibiotic coverage. Ampicillin IV $500 \mathrm{mg}$, Metronidazole $500 \mathrm{mg}$ IV single dose

- Patient to be observed for 2 hours after the procedure

- $\quad$ Patient discharged after 24 hours.

\section{Statistical analysis}

After preparing the master chart and analyzing all the data $p$ value was calculated for most of the tables by chisquare test and $\mathrm{p}$ value for cervical dilation, blood loss and socioeconomic status was calculated by a preinstalled software program. $\mathrm{p}$ value was calculated to know the statistical difference between both the groups. If $\mathrm{p}$ value is $<0.05$ then only the data is said to be statistically significant. 


\section{RESULTS}

In group A out of 100 cases 4 were blighted ovum, 35 were missed abortion and rest of the 61 cases wanted MTP while in group B 3 were blighted ovum, 25 were missed abortion and rest of the 72 cases wanted MTP. p value is 0.257 which is statistically not significant (Table $1)$.

Table 1: Cause for termination of pregnancy.

\begin{tabular}{|ll|l|}
\hline Causes & $\begin{array}{l}\text { Group A } \\
(\mathbf{n = 1 0 0})\end{array}$ & $\begin{array}{l}\text { Group B } \\
(\mathbf{n = 1 0 0})\end{array}$ \\
\hline MTP & 61 & 72 \\
\hline Missed abortion & 35 & 25 \\
\hline Blighted ovum & 4 & 3 \\
\hline Total & $\mathbf{1 0 0}$ & $\mathbf{1 0 0}$ \\
\hline
\end{tabular}

Table 2: Distribution of cases according to gestational age.

\begin{tabular}{|lll|}
\hline $\begin{array}{l}\text { Gestational age } \\
\text { (weeks) }\end{array}$ & $\begin{array}{l}\text { Group A } \\
(\mathbf{n = 1 0 0})\end{array}$ & $\begin{array}{l}\text { Group B } \\
(\mathbf{n = 1 0 0})\end{array}$ \\
\hline 6-8 weeks & 11 & 16 \\
\hline 8-10 weeks & 61 & 53 \\
\hline $10-12$ weeks & 28 & 31 \\
\hline Total & $\mathbf{1 0 0}$ & $\mathbf{1 0 0}$ \\
\hline
\end{tabular}

In group A 11 cases had gestational age of 6-8 weeks, 61 cases had 8-10 weeks of gestational age and 28 cases had 10-12 weeks of gestational age while in group B 16 cases had gestational age of 6-8 weeks, 53 cases had 8-10 weeks of gestational age and 31 cases had 10-12 weeks of gestational age. $\mathrm{p}$ value is 0.44 which is statistically not significant (Table 2).

Table 3: Cervical dilatation.

\begin{tabular}{|c|c|c|c|c|}
\hline \multirow{2}{*}{ Cervical dilatation ( $\mathrm{mm}$ ) } & \multicolumn{2}{|c|}{ Group A (n=100) } & \multicolumn{2}{|c|}{ Group B $(n=100)$} \\
\hline & Before & After & Before & After \\
\hline Os closed & 69 & 9 & 71 & - \\
\hline $4 \mathrm{~mm}$ & 11 & 7 & 15 & 1 \\
\hline $5 \mathrm{~mm}$ & 13 & 3 & 9 & 2 \\
\hline $6 \mathrm{~mm}$ & 7 & 13 & 5 & 12 \\
\hline $7 \mathrm{~mm}$ & - & 45 & - & 13 \\
\hline $8 \mathrm{~mm}$ & - & 17 & - & 14 \\
\hline $9 \mathrm{~mm}$ & - & 3 & - & 49 \\
\hline $10 \mathrm{~mm}$ & - & 2 & - & 4 \\
\hline $12 \mathrm{~mm}$ & - & 1 & - & 4 \\
\hline $14 \mathrm{~mm}$ & - & - & - & 1 \\
\hline
\end{tabular}

Table 4: Blood loss in cases.

\begin{tabular}{|lll|}
\hline Blood loss $(\mathrm{ml})$ & $\begin{array}{l}\text { Group A } \\
(\mathrm{n}=100)\end{array}$ & $\begin{array}{l}\text { Group B } \\
(\mathrm{n}=100)\end{array}$ \\
\hline $15 \mathrm{ml}$ & 7 & - \\
\hline $20 \mathrm{ml}$ & 10 & 6 \\
\hline $25 \mathrm{ml}$ & 13 & 2 \\
\hline $30 \mathrm{ml}$ & 41 & 14 \\
\hline $40 \mathrm{ml}$ & 11 & 5 \\
\hline $45 \mathrm{ml}$ & 3 & 12 \\
\hline $50 \mathrm{ml}$ & 11 & 40 \\
\hline $60 \mathrm{ml}$ & 4 & 6 \\
\hline $70 \mathrm{ml}$ & - & 7 \\
\hline $75 \mathrm{ml}$ & - & 2 \\
\hline $80 \mathrm{ml}$ & - & 3 \\
\hline $100 \mathrm{ml}$ & - & 2 \\
\hline $120 \mathrm{ml}$ & - & 1 \\
\hline Total & $\mathbf{1 0 0}$ & $\mathbf{1 0 0}$ \\
\hline
\end{tabular}

In group A 45 women had dilatation of $7 \mathrm{~mm}$ while in group B 49 women had dilatation of $9 \mathrm{~mm}$. The mean cervical dilation in our study achieved was $6.31 \mathrm{~mm}$ in group A and $8.32 \mathrm{~mm}$ in group B. p value is 0.03 which is statistically significant (Table 3 ).

Table 5: Comparison of adverse events in cases.

\begin{tabular}{|lll|}
\hline $\begin{array}{l}\text { Adverse events in cases } \\
\text { studied }\end{array}$ & $\begin{array}{l}\text { Group A } \\
(\mathbf{n}=\mathbf{1 0 0})\end{array}$ & $\begin{array}{l}\text { Group B } \\
(\mathbf{n}=\mathbf{1 0 0})\end{array}$ \\
\hline Nausea and vomiting & 30 & 8 \\
\hline Loose stools & 32 & 6 \\
\hline Abdominal cramps & 29 & 20 \\
\hline No side effects & 9 & 66 \\
\hline Total & $\mathbf{1 0 0}$ & $\mathbf{1 0 0}$ \\
\hline
\end{tabular}

In group A none of the women had blood loss more than $60 \mathrm{ml}$ while in group B around 15 women had blood loss more than $60 \mathrm{ml}$. In group B one of the cases had blood loss of $120 \mathrm{ml}$. $\mathrm{p}$ value is 0.02 which is statistically 
significant (Table 4). In group B maximum women (66) had no adverse events while majority of adverse events were noted in group A. p value is 0.00 which is statistically significant (Table 5).

Complications like cervical tears or uterine perforation were not observed in either of the groups.

\section{DISCUSSION}

Although suction evacuation is a rapid and relatively safe method for the termination of pregnancy in the first trimester, the frequency of complications increases with increasing pregnancy duration. ${ }^{9}$ Some of these complications e.g. cervical injury and uterine perforation are directly related to the mechanical dilatation necessary for the procedure where as other complications e.g. haemorrhage and incomplete evacuation of pregnancy material may be due to insufficient or difficult dilatation. ${ }^{10}$ However these complications can be avoided by a method that allows a natural and slow dilatation of the cervix. Several studies have assessed the efficacy of PGs with or without mifepristone. ${ }^{11,12}$ This study compares the efficacy and complications of misoprostol and carboprost in cervical ripening for first trimester abortion.

\section{Mean age comparison}

The present study shows most of the patients age is between 21-25 years in both groups. Mean age of women in present study is 24.23 years. $p$ value in our study is 0.598 which is statistically not significant. This is compared to study of Prabhu $\mathrm{S}$ et al in which the mean age in both groups was 29-30 years

\section{Parity comparison}

Present study shows incidence of multigravida is more than primigravida in both the groups. Incidence of multigravida is $76 \%$ and $63 \%$ respectively in group A and $\mathrm{B}$ while incidence of primigravida is $24 \%$ and $37 \%$ respectively in group $\mathrm{A}$ and $\mathrm{B}$. $\mathrm{p}$ value in our study is 0.04 which is statistically significant.

\section{Cause for termination of pregnancy}

Present study shows that out of 200 subjects, 60 women had missed abortion, 7 women had blighted ovum detected on scan and rest 133 women wanted MTP for other reasons like having completed families or for spacing or as contraceptive method. $\mathrm{p}$ value in our study is 0.257 which is statistically not significant.

\section{Mean gestational age comparison}

Present study shows that most of the women had gestational age between 8-10 weeks and the mean gestational age is 8.84 weeks while in study of Vimala Mittal only the women who had gestational age of 9-12 weeks were taken. $\mathrm{p}$ value in our study is 0.44 which is statistically not significant. ${ }^{13}$

\section{Mean cervical dilation comparison}

The mean cervical dilation in our study achieved was $6.31 \mathrm{~mm}$ in group A and $8.32 \mathrm{~mm}$ in group B while the study by Prabhu S showed $7.72 \mathrm{~mm}$ in group A and 7.645 in group B. ${ }^{8}$ In study by Mittal $\mathrm{V}$ mean cervical dilatation was 7.6 in group A while 8.8 in group B. ${ }^{13}$ Study by Jayasheela $\mathrm{M}$ et al found greater cervical dilatation with carboprost compared to misoprost. ${ }^{14}$ Similarly Natrajan PK found satisfactory cervical dilatation with carboprost. $^{15} \mathrm{p}$ value in our study is 0.03 which is statistically significant. In the present study maximum no. of women had cervical dilation of $7 \mathrm{~mm}$ in group A (45) and $9 \mathrm{~mm}$ in group B (49).

\section{Need for additional mechanical dilatation}

In group A $19 \%$ of women had to undergo additional mechanical dilatation while in group B only $3 \%$ of women had to undergo additional mechanical dilatation by Hegar's dilator.

\section{Mean blood loss comparison}

The mean blood loss in our study was $32.25 \mathrm{ml}$ and 48.90 $\mathrm{ml}$ respectively in group A and group B. In study done by Mittal V blood loss observed was almost equal in both the groups. ${ }^{13}$ Study by Bansal R showed less blood loss with carboprost. ${ }^{16} \mathrm{p}$ value in our study is 0.02 which is statistically significant.

\section{Comparison of adverse effects}

The side effects including nausea and vomiting (30\% / $8 \%$ ), loose stools (32\%/6\%), and abdominal cramps (29\% / 20\%) were more in group A as compared to group $\mathrm{B}$ respectively in the present study. In study done by Prabhu S and Mittal V there were no side effects observed in group B. ${ }^{8,13}$ Study by Singh and Megh with $125 \mathrm{mcg}$ had lesser side effects. ${ }^{17} \mathrm{p}$ value in our study is 0.00 which is statistically significant.

\section{CONCLUSION}

Even though use of intravaginal misoprostol is associated with higher blood loss as compared to I.M carboprost which is statistically significant but intravaginal misoprostol achieves more cervical dilatation and causes less adverse events than I.M carboprost which is statistically more significant and therefore intravaginal misoprostol is the drug of choice for cervical priming prior to surgical abortion in terms of both efficacy and safety.

\section{Funding: No funding sources Conflict of interest: None declared}


Ethical approval: The study was approved by the Institutional Ethics Committee

\section{REFERENCES}

1. Sedgh $\mathrm{G}$, Singh $\mathrm{S}$, Iqbal $\mathrm{H}$. Induced abortion worldwide in 2008: levels and trends. The Lancet. 2012;379(9816):625-32.

2. Kulier R, Gulmezoglu AM, Hofmeyr GJ, Cheng LN, Campana A. Medical metods for first trimester abortion. Cochrane Database Syst Rev. 2004;2:CD002855.

3. Niinimaki M, Jouppila $\mathrm{P}$, Martikainen $\mathrm{H}$, Talvensaari-Mattila A. A randomized study comparing efficacy and patient satisfaction in medical or surgical treatment of miscarriage, Fertil Steril. 2006;86:367-72.

4. Zieman M, Fong SK, Benowitz NL, Banskter D, Darney PD. Absorption kinetics of misoprostol with oral or vaginal administration. Obstet Gynecol. 1997;90:88-92.

5. Danielsson KG, Marions L, Rodriguez A, Spur BW, Wong PY, Bygdeman M. Comparison between oral and vaginal administration of misoprostol on uterine contractility. Obstet Gynecol. 1999;93:275-80.

6. Khan RU, EI-Refacy H, Sharma S, Sooranna D, Stafford M. Oral, rectal, and vaginal pharmacokinetics of misoprostol. Obstet Gynecol. 2004; 103:866-70

7. John A, Thomas, Edward J. Keenan. Principles of endocrine. Pharmacol. 1986;3:64.

8. Prabhu S, Aurangabadwalla V, Misri A. Cervical priming prior to first trimester suction evacuation: comparative study. J Evol Med Dent Sci. 2014;3(69):14804-10.

9. Grimes DA, Kenneth F, Schulz, Cates WJ. Prevention of uterine perforation during curettage abortion. JAMA. 1984;251(16):2108-11.

10. Moberg PJ. Uterine perforation in connection with vacuum aspiration for legal abortion. Int J Gynaecol Obstet. 1976;14(1):77-80.
11. McKinley C, Thong KJ, Baird DT. The effect of dose of mifepristone and gestation on the efficacy of medical abortion with mifepristone and misoprostol. Hum Reprod.1993;8:1502.

12. Thong KJ, Baird DT. Induction of abortion with mifepristone and misoprostol in early pregnancy. $\mathrm{Br}$ J Obstet Gynaecol. 1992;99:1004-7.

13. Vimala N, Mittal S, Dadhwal V. Cervical priming with sublingual misoprostol vs. 15-methylprostaglandin F2alpha prior to surgical abortion. Int $\mathbf{J}$ Gynaecol Obstet. 2005;88(2):134-7.

14. Jayasheela M, Lakshmi ARV, Aswini K. Comparative studies on pre-operative inj. Carboprost with misoprostol tablets in 12-25 weeks medical termination of pregnancies. Int J Allied Sci Clin Res. 2015;3(2):218-23.

15. Natrajan PK, Tzingounis VA. Cervical dilatation with prostaglandin F2 alpha for first trimesterabortion. South Med J. 1986;79(7):830.

16. Bala, Singh \& Priyanka, Shrivastava. Cervical Ripening For First Trimester Abortion: A Comparative Study between Misoprostol and Carboprost 125 Micrograms. IOSR J Dental Med Sci.(2017);16:40-2.

17. Singh PD, Megh MG. Carboprost tromethamine in the active management of third stage of labour. Ind Pract. 1995;48:103-5.

Cite this article as: Mathuriya G, Verma N, Pandey S. A comparative study of efficacy and safety of intramuscular carboprost and intravaginal misoprostol for cervical priming prior to first trimester surgical abortion. Int J Reprod Contracept Obstet Gynecol 2019;8:4553-7. 